\section{Illness Causation and Interpretation in a Newar Town}

Madhusudan Subedi

\begin{abstract}
One of the core concerns of medical anthropology is to explore how people in different cultures and social groups explain the causes of ill health, the type of treatment they believe in, and to whom they turn if they do become ill. This article focuses on the understanding of illness causation by the Newars in Kirtipur and their concern about biological and socio-cultural aspects of healthy behavior, and particularly with the ways in which they have been coping in everyday life. The basic method of data collection for this study was formal and informal discussions with the elderly Newar males and females, followed by discussions with youths to explore the variations in their perceptions. The findings show that the understanding of illness etiology is multi-causal. The individual, natural, social, and supernatural causes are not mutually exclusive but are usually linked together in a particular case. In any specific case of illness, moreover, people's explanatory model varies in how they explain its etiology.
\end{abstract}

Keywords: Illness etiology, Newars, cosmology, carelessness, misfortune

\section{Introduction}

The objective of this paper is to explore people's understanding of illness causation and interpretation. Illness is the subjective response of individuals and of those around them (Helman, 2002). It also gives the meanings to that experience. I argue that healing traditions are embedded with cosmogenetic worldviews, as a part of wider concepts about the origin of bodily affliction in general. They are based on beliefs about the structure and function of the body, and ways in which it can function and malfunction. Even if based on biomedically incorrect premises, these explanations or models frequently have an integral logic and consistency (Kleinman, 1980), which often helps the ill person to make sense of what has happened and why.

My argument in this article is that part of people's ideas by which they explain and handle everyday life, can be seen also as their explanations of illness. By doing this, in my view, we will be able to better understand how people describe health and ill health. For example, what are the locally defined illnesses? What are thought to be the causes and the degree of severity and symptoms? What treatments are sought, and from whom? We will also be able to understand their explanation for their state of health; what they identify as important about themselves or their physical or social environment, and what, if anything, they believe can or should be done to protect or enhance their health. Young (1983) has rightly pointed out that medical beliefs are the sets of premises and ideas that enable people to organize their perceptions and experiences of their medical events and to organize their interventions for affecting and controlling these events. They are ways of defining problems and generating solutions to these problems. Following the arguments of Kleinman (1980), Helman (2002), Pigg (1989) and Subedi (2001), I argue that people's explanations for the illnesses that afflict them show the complicated relationships that shape people's lives. Furthermore, by gaining an insider's perspective on culture one can understand the notion of embodied personhood and its effect on the activities of sick people and their families, the relationship between cultural belief and practice and health, ill health, and the sentient human body.

\section{Methods and Materials}

This research was done in Kirtipur called Kipu by the local Newars, one of the oldest settlements, located at the top of a hill in the Kathmandu Valley. The study area is inhabited by the Newars, living in a comparatively compact settlement characterized by the traditional social hierarchy according to which the Pradhans and Amatyas live in the central Layaku palace complex, followed by Shrestha and other middle ranked caste groups. Maharjans, Manandhars, and Tandukaars and lower hierarchies are living on 
the outskirts. History says that the ancient city Kirtipur was founded by Shiva Deva between $1099 \mathrm{AD}$ and $1126 \mathrm{AD}$ and during the reign of the Malla Kingdom, in the 15th century, the city was further developed (Subedi, 2001).

The research has been designed to explore laypersons' systematic perceptions of illness categories in relation to actual behaviors involving those illness and help seeking behavior. The ethnographic work was done in July - December 1999, and March 2010 with the purpose to study the diverse understanding of the relationship between various types of ill health and their signs and symptoms from the point of view of laypersons. The basic method of data collection was formal and informal discussion with the elderly Newar males and females. During the discussion with elderly people, I was assisted by one Newar youth who could speak both Newari and Nepali. Some youths were included in the study to explore the variations in perceptions between young and old generations. Discussions with the elderly and the youths were done separately. A total of ten discussions were done during the later visit; six with elderly people and four with youths. The number of participants in the groups with elderly people ranged from three to six, and with youths from five to eight.

The object of this kind of research is to see things 'from the native point of view' or how local people feel and think and its changing context. It is an attempt to discover meaning from what people have chosen to tell in this particular context with all its distinct properties as a special kind of social interaction. I did not come to the interviews with the idea of 'testing' a particular theoretical proposition. I did not know what I would find. In the interview, I attempted to be as neutral as possible, to allow people to speak without interruption, and to remain open to unanticipated avenues of discussion related to their health, illness, and causes of ill health. Furthermore, I also wanted to explore whether the Newars in Kirtipur share a 'bag of something called culture' (Haaland, 2002) which differs from cultural bags shared by other labeled groups. If the ideas among the same ethnic group vary overtime and generation, the members of particular group thus entertain different ideas among themselves which are learned through social interaction. This aspect of culture highlight it's dynamic, changing quality and gives weight to forces of change and interaction (Trostle, 2005). From this perspective, culture is constantly being transformed.

\section{Findings and Discussions}

\section{Life and the World}

Almost all elderly males and females mentioned that there is a vital force, shakti, a power or energy for balancing the whole universe. God is the source of power. In order to appease the god, people have to perform rituals and make sacrifices. They mentioned that the various rituals such as birth initiation, marriage and death are part of activities that link the visible and invisible world. The visible world is easy to look at, hear or feel. The invisible world, according to them, is a complex one. Their understanding is that whatever happens to the individual in life is strongly linked to the invisible world. On the other hand, the youths, although not highlighting the power of the invisible world but could not deny either. They, however, emphasized more the physical world.

\section{Conceptions of a healthy person}

Almost all informants mentioned that they consider their children to be healthy if they are well and not ill. Eating well as usual, smiling when looking at other's faces, sleeping well, defecating well, and urinating well were the frequently cited features of a healthy child. Some respondents mentioned the proper growth of a child as one of the most important indicators of being healthy. Inability to eat and sleep, cough and fever, crying, loss of weight were the features of an unhealthy child. Both the elderly and the youths had a similar understanding of the concept of a healthy and unhealthy child. Digestion capacity of various types of food was perceived as one of the major indicators of a healthy person, followed by memory capacity, positive attitude towards others, eating and sleeping well, and gaining height and weight. Ill health is linked usually as a part of the much wider conceptual model to explain 'bad luck', 'misfortune, and 'carelessness'. The elderly people highlighted the misfortune and bad luck while the youths were more concerned with carelessness, poverty and social discrimination. 
The concept of 'strong health' and 'weak health' was also linked with the health of the mother. 'A weak mother cannot give a healthy baby', was the frequently cited examples. Likewise, the mother's carelessness during pregnancy is also linked to a weak child. The youths also highlighted the importance of prenatal care and necessity to visit the biomedical practitioners. The elderly, on the other hand, focused on worship of gods and goddesses, preferring specific food and to continue the household work to deliver the healthy child. Some respondents expressed the belief that the strengths and weaknesses of a baby depends on the nature and function of the blood of husband and wife. An occasional weakness, headache, stomach pain, and body pain are taken as normal problems. They are linked to occupational work and seen as temporary problems. Taking a rest for a few hours is the commonly cited response to return back to the normal condition.

\section{Bodily Affliction}

The understanding of bodily affliction in Kirtipur, as in any other community, goes far beyond exploring the ambiguous causes and their appropriate remedies (Foster and Anderson, 1978, Stone, 1976, Devekota, 1884, Pigg, 1995). The understanding of illness causality stems from a distinctive conceptual organization of Newar culture. For the elderly Newars in Kirtipur, an illness is the state in which many worlds partake. Thus illness and affliction are attributed to deeper and often ambiguous causes (Devekota, 1984, Nepali, 1965). People always present logic-rational explanations of illness (causes and consequences of illnesses), and curing techniques are organized accordingly within the broader Newar cultural perspective and social organization.

Participants were asked to describe illness experienced by them during their life time and to consider the causes of these illnesses. Participants broadly categorized two major causes for diseases natural and supernatural. Some stated rog (disease) and dokh (influence of supernatural forces) or the attacks (lageajwima) of supernatural forces as the two major explanations of various diseases. A poor diet, wrong food, too much smoking and drinking, poor housing and sanitation condition, lack of money for food and clothing were the frequently cited causes to become ill. Participants also mentioned bad weather (very hot or very cold), and supernatural forces as the causes of various diseases. In general, etiology or causation of ill health is interpreted in terms of one of the four different worlds: within the individual, the natural world, the social world, and the supernatural world. In many cases, people perceive the illness as the combination of two or more causes, or as the interaction between these various worlds. In this article I have mainly focused on illness etiology of the social and supernatural worlds, an important issue in medical anthropology.

\section{Individual Carelessness: The Causation of Ill Health}

People locate the origin of ill health within the individual that deals mainly with malfunctions within the body related to changes in the diet or behavior. Here the responsibility for illnesses falls mainly, though not completely, on the patients themselves. Ill health is increasingly seen as caused by the people 'not taking care' of one's diet, clothing, hygiene, sexual behavior and physical exercise. Illness is, therefore, often perceived as evidence of such carelessness, and the sufferer feels guilty for causing it. According to Helman (2002) such lay explanations are also common in the western world. In order to prevent and cure these health problems the people must change their food habits and other behaviors such as, for instance, personal hygiene, keeping the house clean, and washing clothes regularly.

The participants in the discussions shared their illness experiences from their childhood and consistently and repeatedly mentioned that, in the past, people used to practice home-based selfmedication, to use various types of herbs, and changing their diet. Visiting the doctors was very uncommon unless the symptoms of illness were very serious or unless someone was almost dead. Elderly discussion participants were keen to tell the interviewer that they were very critical of the contemporary view of treatment among the younger generations: 'When anyone is not feeling well with a minor wound, ache or pain, immediately visits the doctor'. Older people seemed to be particularly critical of their children and grand children's amount of, as well as the causes for, contacting allopathic medical practitioners. They mentioned that the allopathic medicine is effective for some time but that it can become habitual for a person. Their opinion was that once a person starts to take allopathic, the herbal or other type of indigenous medicine does not 
work. They further mentioned that the continuous use of allopathic medicine for the one disease and then for another disease, makes a person weak, and possibly catches another type of disease. On the other hand, the youths were not that much critical towards allopathic medicine. If I compare the patterns of seeking help in 1999 and 2010, I found some differences. There were few medical shops in Kirtipur. Currently, there is a Kirtipur Hospital, about a dozen poly-clinics and many medical shops in the expanded town, Naya Bazar and its surrounding areas. Over-the-counter medicine has been very common, followed by practice of consulting the paramedics and the general practitioners. There are about half a dozen dental clinics, and the Ayurvedic Hospital is established about 20 minutes walking distance from the old town of Kirtipur.

Elderly people mentioned that they seek specific healers based on the nature of their illness symptoms. It is not always the case to blame the victims themselves and sometimes people are unable to find any reason for blaming an individual person. For example, Newars in Kirtipur consider a twitch of a muscle (sarko) to be caused by disequilibrium inside the human body. To cure the illness, they consult a jannemanche who knows the correct spell (sarko mantra). On the other hand, the youth mentioned that they would visit the medical shop or allopathy healer for the treatment of such problems. They also mentioned that they would visit to the jannemanchhe and would continue the medicine taken from a medical shop.

We can see a similar situation in another illness called Janaikai in Kirtipur. In the classical Newari language, the term janai means a sacred cord worn by the twice-born castes in Nepal and kai means infected wounds (khatira-patira) on the skin (Devkota, 1984). The janaikai appears as boils on the body in a circular form like a sacred cord. Stomach, waist, and chest are the bodily parts where janaikai usually appears. The body part where the boils appear first is called chyo (head) and where it appears last is known as nyaphyo (tail). Local people believe that when the boils complete a circle, the person may die. Therefore, when it appears, the person immediately consults a painter or Chitraker. The person draws two figures of the lion (one at the head and another at the tail of the infected area) with an ordinary ink pen. In both figures, the open mouth of the lion faces the boils. People believe that these two figures of the lion will swallow the boils and within a few days the disease will disappear. However, the youths mentioned that people's perception that ill health is caused by their own behavior depends on a number of other factors like socio-economic variables over which the individual has no control.

\section{Natural World and Ill Health}

The natural world includes aspects of the natural environment, both living and inanimate, which are thought to cause ill health. Common in this group are climatic conditions such as extreme cold, heat, wind, rain, water pollution, air pollution, parasitic infection, as do accidental injuries, which also originate in the natural world.

In general, elderly people start home-based self medication to recover as early as possible. Health can be seen as an equilibrium model in which the balance is maintained appropriate to the age and condition of the individual in his natural and social environment. Some youths also said that an illness is triggers by an upset in a balance between, for instance, hot and cold, and that excessive heat or cold has entered the body. Treatment logically attempts to restore the balance through hot and cold food and the treatment aims at neutralizing either excessive heat or cold from the body. The elderly also believed that the diseases are caused by an imbalance of certain elements within the body like air and water. A person who has balanced bodily constitution of hot and cold is not liable to ailment and illness. In order to restore the balance between cold and hot, they take the food or traditional medicine that has the opposite characteristics. They mentioned that hot food should be taken in the cold season and vice versa. It is believed that diarrhea is related to the food consumed by the lactating mother. They believe that it is transmitted to the baby through the mother's milk when the mother eats certain cold foods, which should be avoided during lactation. The youths, however, did not have such information.

\section{Bokshi and Aaankha: The Local Social World}

Blaming other people for one's ill health is a common feature of many societies, where interpersonal conflicts are frequent. In 
Kirtipur the most frequent form of these are bokshi and aankha (evil eyes). The bokshis in Nepal are thought to be the chief causes of any kind of affliction. The complex belief surrounding the bokshi is unambiguously feminine in its association. Bokshis are considered as humans, unlike the other manifestations of the supernatural sphere. The elderly people mentioned that it is religiously wrong to discuss bokshis at all, and that in doing so, they attract their malign attention. On the other hand, youths were not aware of this issue. They simply mentioned that they had heard the words bokshi and aankha.

Some informants said that bokshis go near to the cremation ground and worship the goddess without clothing, thus obtaining power. They can turn into animals at will. In this sense bokshis, of course, are human, but symbolically they are like an extension of violent and dangerous aspects of the goddess in the human world. These females are said to become devotees of goddesses so that they can send her to attack others with illness or barrenness. Anyone who harms others by magical means is considered a bokshi. Bokshis can do this by acting on an item of clothing or hair of victim. But one may also harm simply by looking at them, or particularly at the food they eat. Some elderly female respondents said that anyone can do it, others said it only happens if the onlooker desires to harm. Consensus regarding the bokshi activities could not be found even among the elderly women. The context in which bokshis are encountered is the actual suspicion and naming of known people. In practice it is women, especially old women, and among them especially widows, who are suspected of being bokshis. There are some marked similarities with description of bokshis in other countries (Landy, 1977) and in other groups in Nepal (Stone, 1976; Gellner, 1994; Kristvik, 1999).

The problem of controlling a bokshi is left to the jannemanche, jharphuke vaidys, dhami-jhakri, and Ghubhaju who are supposed to be well versed in counteracting her evil doings. They employ many ways to punish her. People believe that Jharphuke vaidya, jannemanche, dhami-jhankri or Gubhaju catch her through the afflicted person, to reveal her identity and state the reason for evil doings. As a mild course, a healer merely asks her to free the man and promises that she would never again possess him or her. In this case they would not reveal her identity. In some cases, the jannemanche takes stern measures, such as branding the afflicted person's body with spots with a red-hot iron. This burn is supposed to be transferred to the body of the bokshi and people believe that the bokshi in question would be found with an identical burn. Sometimes dried chilly is burnt and it is believed that its smoke would suffocate the bokshi who would come running to the place. In some cases, the jannemanche, by uttering incantations, causes blood to be vomited by his client and this would result in actual blood being vomited by the bokshi at her place, so the belief runs. However, I could not confirm these cases.

There are different ways of punishing bokshis. It is easy to see news about bokshi appearing frequently in the government's newspapers as well as in other newspapers. There are, in my view, thousands of such cases in Nepal, which go unnoticed, unreported or under-reported. Healers like dhami, jhankri, gubhaju, jannemanche, jharphuke, Ma, and so many others (depending on availability and beliefs of the different ethnic groups in Nepal) use their own method to punish the bokshis to drive the spirit of the bokshi away. If a child, cattle or anybody dies, a woman is targeted as a bokshi who caused the death of child, cattle or any person. She is beaten, humiliated, and forced to feed on human feces. If she survives at all, unable to bear the insult, she hardly ventures out of her house (Subedi, 2001). There are many instances of feeding human excreta to a woman on the charge of being bokshi in different districts of Nepal has been frequently reported in different media. Elderly people in Kirtipur make a connection between jannemanche and bokshis. They believe that the relation between jannemanche and bokshi is close. It is often said that the knowledge which jannemanche must have is the same, only stronger than that of bokshis. Jannemanche knows how to cause harm, and how to undo it. Many healers are believed to have mastered the bokshi mantra in order to combat evil powers. Likewise, bokshis are thought to have healing capabilities. The basic knowledge is the same whether it is subidhya (good knowledge) or kubidhya (bad knowledge), the healing depends on how it is used. Some people said that a female jannemanche is the same as bokshi. There seems to be an agreement about the idea that jannemanche and bokshi hold the same kind of power, but the 
jannmanche is said to have one mantra more than the bokshi, which gives them the upper hand. The youths have different attitudes towards bokshi and supernatural power. They give different reactions toward dhami, jhankri or jannemanchhe. Traditionally, dhami and jhankri are supposed to be psychic healers and are hence seen with both respect and fear (Allen, 1976; Peters, 1979; Maskarinec, 1995; Miller, 1997) in rural parts of the country.

As far as healing goes, the jhankris do enjoy some degree of respect mainly due to ignorance among people. The youths were of the opinion that pointing out bokshis and persecuting them at times even to the point of killing them or making them commit suicide, simply cannot be allowed. The dhami, jhankri or jannemanchhe, whoever it is, should be punished. According to them, this is one of the ways of measuring the country's backwardness. Superstition reflects the predominance of illiteracy and ignorance in the lives of people. Leave aside arresting the dhami, jhankri or any types of healers who point out a woman as bokshi, are garlanded with money. They further argue that superstitious belief of feeding human excreta to women on the charge of being a bokshi still continues because the culturally constructed ideas are deeply rooted in the mind of Nepali people.

\section{Supernatural Causes of Illness}

A belief in the spiritual world is very strong among the Newars, just like among other inhabitants of the valley or in the country as a whole (see, for example, Nepali, 1965; Hitchcock and Jones, 1976; Stone, 1976; Blustain, 1976; Devekota, 1984; Pigg, 1995; Gellner, 1994). Kathmandu is the city of gods and goddesses and the haunting place of spirits and ghosts. Almost all the elderly discussion participants in Kirtipur believe that these bhut, pret, khya and other hungry ghosts can bring disease and death to those who neglect them, blight to crops, fires to houses, barrenness to wives, and disease and drought to the village. The elderly people classify the god and goddess, demon, bhut (ghost), pret, masan, and bayu as supernatural beings. The notion of the shakti (power) is the defining characteristic of supernatural beings. The basic characteristic of any god, demon or ghost is the power that he/she controls and represents, the fact that he/she is, in essence, power.
Given the premise that "supernatural beings are powerful beings", I shall describe the roles underlying the ascription of power, the behavior of power-filled beings, and thereby ritual behavior, by examining the way in which power is used, explained and dealt with by the people. This includes three related questions: Which specific aspect of their lives do the people believe in? How do they perceive the ways in which these powers are distributed among their deities? How do powerful beings function in controlling the relevant aspect of life?

The noun in Nepali that comes close to including all possible powerful beings is devi, devata, which is defined to include gods and goddesses. The common characteristic of all Kirtipur deities is shakti (power). The Nepali term closest in meaning to shakti is bal, but bal implies a physical strength in contrast to shakti, which implies a spiritual power, although that spiritual power can be manifested physically. Thus a person is said to have bal but not necessarily shakti, and the gods have shakti but not necessarily bal. Temples and shrines are supposed to be shakti griha (power stations) but only spiritual powerhouses. Each item of the universe has its share of shakti (power). As Marriott and Inden (1972 quoted in Wadley, 1975:55) note, "every genus of living beings shares from the moment of its generation its defining qualities (guna), powers (shakti), and actions (karma)". Thus every being of the universe embodies its share of power. Some beings have more power than others (Dietrich, 1998). Those beings with more shakti are the powerful beings (supernatural beings), beings with less shakti are no so powerful. Moreover, because every being in the universe embodies some power (by definition), everything in the universe is potentially a powerful being. However, all gods and goddesses and other supernatural beings are not equally powerful.

An examination of a few Kirtipur deities should clarify this point. Bagh Bhairav, Indriyani, Uma-Maheshwar, Ganesh, Shiva, Laxmi, and Saraswati are at any time and in any place powerful. There are shrines and statues for all these deities and people offer regular puja (worship) for them on auspicious days. These deities do not cause illness to an individual without reasons. They are the protective forces for the place and people. If an individual offends them, he/she suffers from illness. Under such circumstances, 
he/she prays to these deities to be saved from their designs. They may promise the puja (worship) to the affiliated deity at a latter date, which must be fulfilled. These deities may withhold their protection for an individual being attacked by evil forces. Thus villagers offer regular offerings or worship. Bagh Bhairav Temple is dedicated to God Bhairav in the form of a tiger. This god is regarded as the guardian of Kirtipur and the locals call it Ajudeu, a grandfather god. Nagpanchami (snake's fifth) and worship on Rakshya Bandhan (tying on protection) are marked powerful beings; like all beings they have their given power (shakti) but they cannot be recognized as really powerful except in this particular situation or other situations involving ritual activity. Likewise, the boy and girl in the marked situation (special situation) of bride and groom are recognized during the period of marriage ceremonies as god and goddess. In Kirtipur, they are considered Ram and Sita-so much so that their elders touch their feet.

People in general believe that all the gods and goddesses affect their life, although their shrines are located outside their villages. Harati ma, a goddess of smallpox and measles, whose shrine is at Swyambhu in Kathmandu is worshiped regularly. Even though smallpox in Nepal has been eradicated, this practice is continuing even today. Similarly, Khayatama Deo (the protector of children) of Bhat-Bhateni is also worshiped to ask for protection. The Unmateshwar Bhairav of Gyaneshwar, Sankkata Deo of Tebahal, Bijeshwari of Shobha Bhagati, Maste Narayan of Mache Gaon, and several other gods and goddess are also worshiped so that they could continue to protect people. Machhendranath is considered as the provider of rain and grain to the people of the Kathmandu Valley. Likewise, one can see a symbol of worship, like a round plate of stone, on the doorstep of most Newar houses, regarded as a symbol of Kumar, son of Shiva and Parbati. Newar worship this symbol at the doorstep before other daily household worship. This worship is found to be common only among the Newars.

Almost all the elderly participants mentioned that the gods, ghosts, and demons have powers of varying kinds, whose primary characteristic is their possible control over human conditions. Similarly, a bride and groom are power-filled because they represent fertility and prosperity, the future growth of the family. A snake is powerful because it can kill. All that exists in the universe contains some power and can be part of a Hindu pantheon. Thus, when discussing the Newari cultural conceptions we must recognize that there is no native conception of a bounded domain of "region" or the spiritual. People believe that gods and goddesses are superior to human beings and thus must be worshiped. In return, they bestow benefits on men.

Worship of nagas (serpent gods) is found to be common among the Newars. The traditional story is that when Manjushree drained the lake, the then Kathmandu, most nagas left abode except for one Karkotaka naga who today is believed to dwell in Tau Daha (a lake in the southern outskirts of the valley; it was because of Karkotaka naga the valley retained its needed water or it would have been completely dry (Nepali, 1965; Gurung, 2000). In the events of drought, Newars in Kirtipur go to Tau Daha and worship Karkotaka. When one gets rashes on the body, one needs to worship the nagas. The elderly people believe that the nagas ensure the peace, bestow riches, and protect the house. The youths were not aware of this type of explanation of nagas and their role for peace and protection.

The ghost-like creatures, associated with the spirits of the dead, are often called pret or bhut-pret (from the Sanskrit term preta, locally pronounced pret). Pret refers to the particular spiritual principle or entity that represents the continuation of a person after death, and that undergoes various transformations. For the first twelve days after death the spirit is perceived to be in a pret form. Pret is variously perceived as being an ancestor spirit or pitr, or of being safely on its way to some place of judgment, or state of reincarnation. The corpse is also referred to as pret. There are various mishaps that can prevent the proper passage through and beyond the pret stage, and the pret then will become a troublesome earth-bound ghost. A person who was not ready to die or did not want to may become a permanent pret. 'Someone who dies in such a way that the proper ritual can not be done - such as an accident away from the home or whose death is considered unnatural - can also become such a pret', was the common notion of elderly people. 
The presence of these ghosts is often harmlessly manifested in such events as a window or door moving by itself or a chair shifting position. They usually stay around their former homes, and will not harm family members if as many as possible of the proper postdeath rituals have been performed. Similarly, the ghosts and spirits cluster at cross roads, inhabit the woods and fields outside the city, lurk in the dark, and are driven away by bright lights. Sometimes they may invade a home but usually in outside shadowy areas. An encounter with them is usually a matter of some accidents or inadvertent mistake. They are, however, more malevolent varieties that may enter a person and consume them from the inside, causing them to lose weight and become ill, requiring the service of special spirit exorcists.

There are still other beings that for some people are kinds of bhuts, for others kinds of prets, and for still others neither pret nor bhut but independent beings. Among these is the Khya, which exists in two forms, white and black. The white is benign and guards the house from other spirits. It sometimes may snuggle up to a person, and produce a tickling feeling. The black one may produce frightening nightmares. They may press on people's chest during sleep, making it difficult to breathe or to move. While for some people Khyas are independent spirits, but not bhuts, for others they are a kind of bhut, for still others they arise from a body that has not been thoroughly cremated so that some flesh remains. Similarly, the stone and the crossing roads, and the divinity thought to be located there are called chhwasa. The chhwasa is sometimes considered as a divinity in itself, other times among the more erudite as the seat of the tantric goddesses, Matangi. Some old respondents mentioned that Chhwasa is related to the death spirit of the family, grandfather and grandmother (aju-aji). The belief is that aju-aji attacks human beings only when their hunger is not appeased. When one suspects their attack, the hunger must be satisfied, offering a small share to them. It is believed that small children are most vulnerable but aju-aji can attach adults too. Sudden stomach pain, headache, bleeding through mouth, and diarrhea were stated as the key signs and symptoms of attack by aju-aji.
The chhwasa is one of the places where polluting materials are deposited so that they no longer will be dangerous or problematic. The clothes worn by a person at the time of or just before death are gathered up and thrown to the chhwasa. Certain remains of formal feasts are discarded there. Chhwasa lies at a crossroad and is thought to be gathering place for potentially harmful spirits. It is also the place where people discard cloths soiled by menstruation, the umbilical cords of newborn infants, clothes of the dead, and food as offering to potentially harmful spirits. The chhwasa not only can observe the polluted materials placed on it, materials that would be strongly contaminating if placed in any ordinary space within the city, but is also said to protect the area around it (Devkopta, 1984). However, the observation of the researcher showed that the practice of throwing polluted materials at the chhwasa has decreased compared to past. This may be due to the practice of collecting garbage by Kirtipur Municipality. The main chhwasa are said to protect the entire village. This combination of power to absorb polluting materials and protect through power is generally a characteristic of a class of deities, the dangerous deities, of which the chhwasa is a member.

\section{Mental Health and Symbolic Healing}

Loss of memory power, repetition of similar activities, aggressiveness, misbehaving with family members and friends, dramatic changes in eating and sleeping habits, poor grades despite hard work and strong efforts, damaging property, are categorized as the problems related to dimag (mental). In such cases, the patient is surrounded by the family members and friends. The mental illnesses are explained in terms of possession by bhut, prêt, pisach, bayu, bokshi, and gods. This is also linked to the 'bad karma, bhagya and mohini' of a person. Similar findings are stated in Jirels of Jiri (Tausig et al, 2000). The attitude of people towards mentally suffered persons was found to be negative and stigmatized. The suffering individual is taken to the Dhami-Jhankri and Janne manchhe, and to various temples for worshiping the god and goddesses. Many elderly people held the view that such problems are hereditary. Those people being aware of mental illness thought that such illnesses are different from other types of health problems like accident and fracture, fever, vomiting, all of which could be cured. They believe that mental illness can be 
repeated occasionally. The youths mentioned that such problems often are cured by visiting psychiatrist, worshiping the gods and goddess, and visiting the local healers.

\section{Expansion of Biomedicine in Kirtipur}

Allopathic medicine in Nepal has been practiced from the middle of the 18th Century. According to Dixit (1995), the first reference to the allopathic practitioner in this country occurs in an account of the siege of Kirtipur by King Prithvi Narayan Shah in 1766/67. It was Swarup Ratna, the King's brother, who had been cured of a wound by one Michael Angelo, a Capuchin monk (Dixit, 1995).

Prithvi Bir Hospital, the first allopathy public hospital of Nepal was built in 1890 at Kathmandu which initially started at NorthWestern corner of the Ranipokhari. The total number of beds was only 30. Currently, many private hospitals and medical colleges are established in almost all towns of Nepal. Health sector has been one of the most successful businesses in private sector. Over-thecounter medicine and non-doctor prescribing have been very common in Kirtipur. It was also observed that prescription and the use of antibiotics is rampant and the patients were taking half of the doses of medicine as an attitude of wait and see. Visiting the medical shop of afno manche (kin group or relatives), followed by going to visiting trustworthy persons and hospitals was found to be more common. For the last twenty five years I have been observing Kirtipur as a student and researcher along with the permanent residents. The allopathic health care system has been blooming rapidly in Kirtipur, and a proposed Puspa Lal Medical College and Teaching Hospital is going to be started soon in Kirtipur. Practice of consulting the government doctors and private hospitals outside Kirtipur has been more common. Biomedicine has become a significantly popular practice for overcoming disease identification and techniques of treatment. It has been commodified and commercialized, and the poor has to find cheaper services.

\section{Conclusion}

The perceptions of a healthy person and process of becoming ill consists of a combination of subjective experiences of the physical or emotional changes, and the confirmation of these changes by other people. One can easily observe the different categories of the concept of a healthy and unhealthy body, understanding of illness causation, interpretation and the preventive as well as curative healing practices. The understanding of illness etiology among the Newars in Kirtipur is multi-causal, that is, several causes are acting together. This means that individual, natural, social, and supernatural causes are not mutually exclusive, but are usually linked together in a particular case. In any specific case of illness, people emphasize different causes when they attempt to explain its etiology. Moreover, the explanatory model varies according to people's age group and to the exposure of various medical traditions, especially the allopathic medicine. This clearly shows that the various members of particular group reflect different health beliefs and practices among themselves. Belief and practices are not consistent essential features to introduce certain ethnic group. Cultural categories not only change through time, but they also can be differentially manipulated by people interacting within a web of relationships embedded in a larger material and social context. Such knowledge will help for developing more appropriate health policies, deepen understandings of disease causation and treatment, and create more effective actions to enhance health and prevent disease.

\section{Acknowledgements}

Information used in this paper were mainly collected in the year July-December 1999 for my M Phil thesis in Social Anthropology, University of Bergen, Norway, and in March 2010 for further exploration and validation. I am grateful to the Norwegian Agency for International Development and Cooperation (NORAD) for financial support. I would like to thank Professor Gunnar Haaland for his insightful comment during my stay in Norway. Professor Marit Bakke deserves special thanks for her feedback, suggestions, and encouragement for shaping this paper into this form.

\section{References}

Allen, Nicholas (1976). Shamanism among the Thulung Rai (pp 124-140). In: John T. Hitchcock and Rex L. Jones (eds.) Spirit Possession in the Nepal Himalayas. Delhi: Vikas Publishing Press. 
Blustain, Harvey S. (1976). "Levels of Medicine in a Center Nepali Village.” Contributions to Nepalese Studies. Special Issue, Vol.3, pp 83-105.

Devekota, Padam Lal (1984). "Illness Interpretation and Modes of Treatment in Kirtipur”. Contributions to Nepalese Studies. Vol. 11(2): pp 11-20.

Dietrich, Angela (1998). Tantric Healing in Kathmandu Valley: A Comparative Study of Hindu and Buddhist Spiritual Healing Traditions in Urban Nepalese Society. Delhi: Book Faith India.

Dixit, Hemang (1995). The Quest for Health. Kathmandu: Educational Enterprise.

Foster, George and Anderson, Barbara (1978). Medical Anthropology. New York: John Wiley and Sons, Inc.

Gellner, David N. (1994). "Priest, Healers, Mediums and Witches: The Context of Possession in Kathmandu Valley, Nepal.” Journal of Royal Anthropological Institute. Vol. 29(1) pp 27-48.

Gurung, Poonam (2000). Bungmati: The Life World of Newar Community explored through the natural and social life of Water. Unpublished Thesis: Faculty of Social Science. University of Bergen, Norway.

Haaland, Gunnar (2002). Culture, Society and Nature: Reflection on Some Contribution from the Arun Valley (Pp 191-200). In Ram P. Chaudhary, Bhim P. Subedi, Ole R. Vetaas and Tor H. Aase (eds.) Vegetation and Society: Their Interaction in the Himalayas.

Helman, Cecil G. (2002). Culture, Health and Illness (Fourth Edition). London: Arnold.

Hitchock, John T. And Jones, Rex (eds.) (1976). Spirit Possession in the Nepal Himalayas. New Delhi: Vikas Publishing House.

Kleinman, Arthur (1980). Patients and Healers in the Contexts of Culture. Berkeley: University of California Press.

Kristvik, Ellen (1999) Drums and Syringes; Bibliotheca Himalayica; Series III; Vol. 7; Kathmandu.

Maskarinec, Gregory G. (1995). The Rulings of the Night: An Ethnography of Nepalese Shaman Oral Texts. Kathmandu: Mandala Book Point.

Miller, Casper J. (1997). Faith Healers in the Himalaya. Delhi:
Book Faith India.

Landy, David (ed.) (1977). "Traditional Curer Under the Impact of Western Medicine.” In Culture, Disease and Healing: Studies in Medical anthropology. New York: Macmillan Publishing Company Co.

Nepali, Gopal Singh (1965). The Newars: An Ethno-Sociological Study of a Himalayan Community. Bombay: United Asia Publication.

Okada, Ferdinand (1976). "Notes on two Shamans-curers in Kathmandu.” Contributions to Nepalese Studies. Special issue, Vol.3. pp 107-112.

Peters. Larry G. (1979). Shamanism and Medicine in Developing Nepal. Contributions to Nepalese Studies, Vol. 6(2), pp 2743

Pigg, Stacy Leigh (1989). Here, There and Every Where: Place and Person in Nepalese Explanations of Illness. Himalayan Research Bulletin. Vol. IX(2) pp.16-23.

.....(1995). “Acronyms and Effacement: Traditional Medical Practitioners (TMP) in Internal Health Development." Social Science and Medicine. Vol. 41(1): pp 47-68.

Stone, Linda (1976). "Concept of Illness and curing in a central Nepal village.” Contributions to Nepalese Studies. Special issue, Vol.3. pp 55-80

Subedi, Madhusudan (2001). Medical Anthropology of Nepal. Kathmandu: Udaya Books.

Tausig, Mark et al. (2000). Mental Illness in Jiri, Nepal. Contributions to Nepalese Studies. Special issue, pp 105115.

Trostle, James A. (2005). Epidemiology and Culture. Cambridge Studies in Medical Anthropology, Cambridge University Press.

Wadley, Susan Snow (1975). Power in the Conceptual Structure of Karimpur Religion. University of Chicago Studies in Anthropology, Department of Anthropology, University of Chicago.

Young, Allan (1983). The relevance of Traditional Medical Cultures to Modern Primary Health Care. Social Science and Medicine, Vol. 17(16), pp 1205-1211 